\title{
Hepatic ultrasonic changes in workers exposed to perchloroethylene
}

Carl A Brodkin, William Daniell, Harvey Checkoway, Diana Echeverria, Janet Johnson, Keith Wang, Roya Sohaey, David Green, Carrie Redlich, David Gretch, Linda Rosenstock

Department of Medicine

C A Brodkin

L Rosenstock

Department of

Environmental Health

C A Brodkin

W Daniell

H Checkoway

L Rosenstock

Department of

Radiology

J Johnson

K Wang

D Green

Department of

Laboratory Medicine,

University of

Washington, Seattle,

WA

D Gretch

Battelle Seattle

Research Center,

Seattle, WA

D Echeverria

Swedish Medical

Center, Department

of Radiology, Seattle,

WA

$\mathrm{K}$ Wang

R Sohaey

University of Utah,

Department of

Radiology, Salt Lake

City, Utah

$R$ Sohaey

Yale University,

Department of

Medicine, New Haven,

CT

C Redlich

National Institute for

Occupational Safety

and Health,

Washington, DC

L Rosenstock

Correspondence to:

C A Brodkin, Occupationa

and Environmental

Medicine Program,

University of Washington,

ZA-66, 325 9th Ave, Seattle

WA 98104, USA.

Accepted 19 June 1995

\begin{abstract}
Objective-To determine if subclinical hepatotoxicity is associated with exposure to perchloroethylene at concentrations commonly experienced in the workplace, and whether surveillance with serum hepatic transaminase activity underestimates such effects.
\end{abstract}

Methods-Hepatic parenchymal echogenicity on ultrasonography and serum hepatic transaminase activity were compared in 29 community based dry cleaning operators exposed to perchloroethylene, and a control group of 29 non-exposed laundry workers. Perchloroethylene exposure was assessed by work history and air monitoring.

Results-Mean hepatic transaminase activities were minimally increased in dry cleaners compared with laundry workers. Increased alanine aminotransferase activities, between 1.0 and 1.5 times the normal limits, were found in five of $27(19 \%)$ dry cleaners compared with one of $26(4 \%)$ laundry workers. In contrast, diffuse parenchymal changes in echogenicity, as determined by hepatic ultrasonography, were increased nearly twofold in dry cleaners, occurring in 18 of $27(67 \%)$ dry cleaners compared with 10 of $26(39 \%)$ laundry workers $(P<0.05)$, and were most strongly associated with increased perchloroethylene exposure in older dry to dry or wet transfer operations (odds ratio $4 \cdot 2,95 \%$ confidence

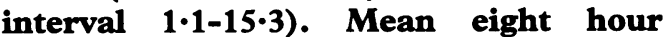
time weighted average perchloroethylene exposure for dry cleaners was $16 \mathrm{ppm}$, which is less than the permissible exposure limit of $100 \mathrm{ppm}$ in the United States.

Conclusions-It was concluded that mild to moderate hepatic parenchymal changes occur more frequently in workers exposed to perchloroethylene than in populations not exposed to chemical solvents, and that these effects are underestimated by serum hepatic transaminase activity.

(Occup Environ Med 1995;52:679-685)

Keywords: hepatotoxicity; ultrasonic imaging; aminotransferases; perchloroethylene

Halogenated alkane solvents, such as carbon tetrachloride and tetrachloroethane, have largely been replaced by less toxic halogenated alkene solvents, such as perchloroethylene and a variety of non-halogenated compounds. None the less, perchloroethylene at exposure concentrations greater than 100 ppm has been shown to cause acute hepatotoxicity in humans. ${ }^{1-5}$ Little is known about the occurrence of chronic hepatotoxicity at low levels of exposure to perchloroethylene experienced currently in occupational and environmental settings. In dry cleaning and metal degreasing processes in particular, an estimated 500000 workers in the United States are occupationally exposed to perchloroethylene $^{6}$ (also known as tetrachloroethylene), and one million people living close to dry cleaning shops may be exposed to generally low levels from surface and ground water or ambient air contamination. ${ }^{7}$

Epidemiological assessment of hepatotoxicity in populations exposed to solvent has been limited by difficulties in obtaining histological data, which require invasive biopsy. In general, detection of subclinical hepatic injury in workplace surveillance programmes has relied on measurements of activities of serum hepatic transaminases. Serum alanine aminotransferase (ALT) and aspartate aminotransferase (AST) may not reflect hepatic injury in the absence of significant necrosis and inflammation, thus early hepatotoxic effects may be underestimated. Histological samples obtained from workers exposed to solvents who had only mild biochemical abnormalities have shown prominent fatty change, or steatosis, with varying degrees of inflammation and fibrosis, ${ }^{8-10}$ which suggests that parenchymal changes may be an early feature of solvent induced liver injury. These effects may be identified more sensitively by non-invasive imaging methods, which allow detection of fatty and fibrotic changes.

Hepatic ultrasonography is a non-invasive technique that has been shown to characterise parenchymal changes effectively, and has correlated well with histological abnormalities of steatosis and fibrosis of non-occupational origin. ${ }^{11-13}$ Moreover, a significant exposureresponse relation between sonographic parenchymal changes and exposure to vinyl chloride monomer has also been found in an occupational setting. ${ }^{14}{ }^{15}$ Ultrasonography may thus provide a more sensitive method than biochemical tests for detecting subclinical hepatic disease. We performed hepatic ultrasonography and measured serum hepatic transaminase activity in dry cleaning operators exposed to perchloroethylene. For compari- 
son we measured these variables in laundry workers not exposed to perchloroethylene or other solvents. Our objectives were to assess evidence of subclinical liver injury by ultrasonography in relation to perchloroethylene exposure, and to compare findings with those obtained by the conventional approach of transaminase measurement.

\section{Methods}

SUBJECT SELECTION

The study was conducted at dry cleaning and laundry shops in Seattle and the Puget Sound region of Washington State. Participation was requested from 55 dry cleaning operators exposed to perchloroethylene and 56 laundry workers not exposed to solvent chemicals between September 1991 and February 1992. Thirty seven (67\%) dry cleaners and 46 (82\%) laundry workers were recruited. Workers were eligible if they had worked in their trade for at least six continuous months and met the following criteria, specified to exclude people at risk of liver disease from non-occupational causes: (a) random blood sugar less than $140 \mathrm{mg} \%$, and no history of diabetes mellitus; (b) alcohol use, reported from a structured face to face questionnaire, of less than $30 \mathrm{~g} /$ day $^{16}$ (less than two drinks a day averaged over the previous six months), with maximum past alcohol use less than $75 \mathrm{~g} /$ day (averaged over any six month period), and no history of alcoholism; (c) no history of hepatitis or jaundice; $(d)$ no history of blood transfusions; (e) no use of medications known to be for significant hepatotoxicity (isoniazid, dilantin, nitrofurantoin, and methotrexate); $(f)$ no current pregnancy; ( $g$ ) no history of notable solvent exposure from non-occupational sources or previous occupations; $(h)$ weight less than $125 \%$ of ideal body weight ${ }^{17}$; and (i) exclusive use of perchloroethylene within the past five years among exposed subjects.

Twenty nine $(78 \%)$ recruited dry cleaners and $29(63 \%)$ laundry controls met eligibility criteria for enrollment. Exposed subjects were recruited from 16 community dry cleaning establishments and controls were similarly recruited from two industrial laundries $(n=25)$, one laundry drop shop $(n=2)$, and one carpet cleaning shop $(n=2)$. All subjects participated voluntarily and provided informed consent, and the study was conducted with advanced approval from the Human Subjects Review Committee of the University of Washington.

\section{EXPOSURE ASSESSMENT}

The dry cleaning process requires three basic procedures: cleaning, extraction of solvent, and drying. As well as loading and unloading machines, operators also perform routine maintenance procedures such as solvent tank loading, and filter and gasket replacement. Perchloroethylene exposure is greatest among operators who use "transfer" equipment, where saturated garments are transferred manually from a washer/extractor to a sepa- rate drying unit. Relatively lower levels of exposure occur among "dry to dry" equipment operators, where the entire process is performed in a single enclosed unit. ${ }^{18}$ Technological improvements in local exhaust ventilation, enclosed piping, and cooling condensers, as well as reduced maintenance needs have resulted in lowered exposure concentrations in recently manufactured equipment; emission reductions of $40 \%$ to $90 \%$ have been reported in shops that use modern dry cleaning equipment. ${ }^{19}$

All subjects completed a self administered questionnaire that reviewed current and previous occupations, work activities, duration of employment, and health history. Among dry cleaning operators, subacute exposure to perchloroethylene was assessed qualitatively both by questionnaire and by direct subject interview, to determine the dry cleaning process (transfer $v$ dry to dry) and how recently dry cleaning equipment had been installed. Dry cleaners who used dry to dry equipment installed within the previous three years were classified as having low exposure; dry cleaners who used transfer equipment or dry to dry equipment installed more than three years previously were classified as having high perchloroethylene exposure. Current exposure concentrations were estimated by personal air sampling in a subgroup of 19 dry cleaning operators. All samples were collected on $3 \mathrm{M}$ Model 3500 passive badge dosimeters (3M Corporation $($, Minneapolis) for a full work shift within eight weeks of biochemical and ultrasound sampling, standardised to an eight hour time weighted average and analysed by standard National Institute of Occupational Health and Safety (NIOSH) methods for perchloroethylene. ${ }^{20}$

An index of cumulative exposure to perchloroethylene was constructed by weighting years spent in wet transfer and dry operations, respectively, by 1.0 and 0.5 . The summed products of duration of employment and job specific weights thus were used as perchloroethylene dose surrogates.

BIOCHEMICAL AND SEROLOGICAL TESTS

Serum alanine aminotransferase (ALT), aspartate aminotransferase (AS), $\gamma$-glutamyl transferase (GGT), alkaline phosphatase (AP), total and direct bilirubin, and viral serologies were determined at the time that hepatic ultrasonography was performed. Biochemical and serological measurements were performed at hospital based clinical laboratories (Swedish and University of Washington Medical Centers). Biochemical values greater than the standard clinical reference range for the laboratory population were defined as abnormal (table 2). Serological tests included hepatitis B core antibody, hepatitis B surface antigen, and hepatitis C antibody (ELISA II method).

\section{HEPATIC ULTRASONOGRAPHY}

Limited hepatic ultrasonography was performed at the worksite on the final afternoon of the working week. Sonography was 
Figure 1

Ultrasonographic photographs, sagittal view of the right hepatic lobe and kidney in three subjects, with $(A)$ normal parenchymal echogenicity, vascular architecture, and normal diaphragmatic appearance (beam penetration); (B) mild parenchymal changes, with increased echogenicity, poor vascular markings, and diaphragmatic resolution (decreased beam penetration); $(C)$ moderately severe parenchymal changes, with notably increased echogenicity, blurring of vascular markings, and poorly visualised diaphragm low beam penetration).
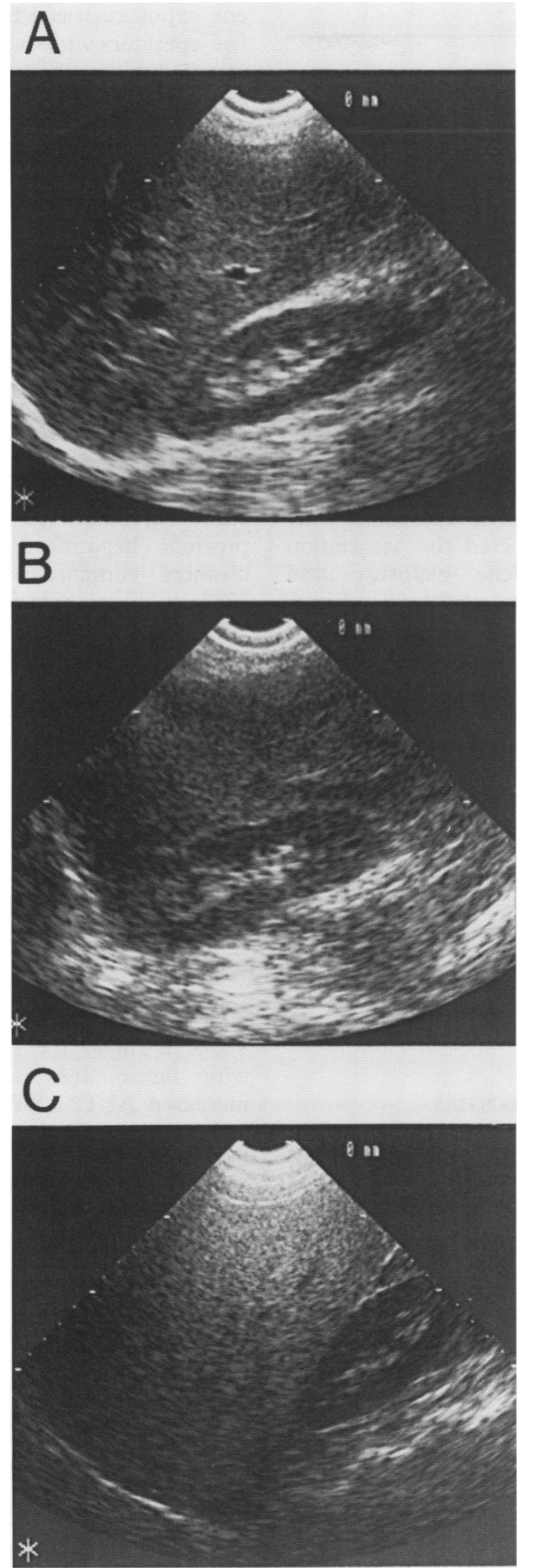

performed by an experienced certified sonographer (DG), who used an ATL Ultramark 4+ (Advanced Technology Laboratories; Bothell, WA) with a $3 \mathrm{MHz}$ long focus transducer. Hard copy photographs were taken in three transverse and three longitudinal planes, including comparison of renal and hepatic echogenicity. The sonograms were then independently reviewed by three experienced radiologists (KW, J, RS) with special ultrasound expertise. The reviewers were blinded to the exposure and
Table 1 Demographic characteristics (mean (SD))

\begin{tabular}{|c|c|c|}
\hline & $\begin{array}{l}\text { Non-exposed } \\
\text { Laundry } \\
\text { workers } \\
(n=29)\end{array}$ & $\begin{array}{l}\text { Exposed } \\
\text { Dry cleaning } \\
\text { operators } \\
(n=29)\end{array}$ \\
\hline $\begin{array}{l}\text { Age (y) } \\
\text { Sex }(n \%)\end{array}$ & $38(10)$ & $46(16)^{\star}$ \\
\hline $\mathbf{M}$ & $14(48)$ & $17(59 \%)$ \\
\hline F & $15(52)$ & $12(41 \%)$ \\
\hline Height $(\mathrm{cm})$ & $171(99)$ & $168(117)$ \\
\hline Weight (kg) & 72 (13) & 71 (17) \\
\hline $\begin{array}{l}\text { Body mass index } \\
\left(\mathrm{kg} / \mathrm{m}^{2}\right)\end{array}$ & $25(4)$ & $25(3)$ \\
\hline Ethnicity $(\mathrm{n}(\%))$ : & & कर \\
\hline White & $21(73 \%)$ & $18(62 \%)$ \\
\hline Asian & $2(7 \%)$ & $7(24 \%)$ \\
\hline Black & $1(3 \%)$ & $4(14 \%)$ \\
\hline Hispanic & $4(14 \%)$ & 0 \\
\hline Native American & $1(3 \%)$ & 0 \\
\hline Education (y) & $13(2)$ & $12(2)$ \\
\hline $\begin{array}{l}\text { Duration of } \\
\text { employment (y) }\end{array}$ & $5(6)$ & $20(18)^{\star}$ \\
\hline $\begin{array}{l}\text { Estimated alcohol } \\
\text { consumption (g/week): }\end{array}$ & & \\
\hline (last 6 months) & $53(82)$ & $37(45)$ \\
\hline $\begin{array}{l}\text { Maximum intake } \\
\text { (any } 6 \text { months) }\end{array}$ & 95 (105) & $95(120)$ \\
\hline
\end{tabular}

$\star \mathrm{P}<0.05$.

demography of the subjects. The sonographic hepatic appearance was rated by a modified method described by Scatarige and associates, ${ }^{21}$ as "normal", "mild", or "moderate to severe" parenchymal change (fig 1). Full agreement between radiologists was obtained for $32(55 \%)$ subjects, and agreement within one grade was obtained for 58 subjects ( $98 \%)$, with weighted $\kappa$ coefficients for the between radiologist pairs ranging from 0.59 to 0.65 , indicating very good agreement beyond chance. ${ }^{22}$ In cases where readings differed, the sonogram was rated at the level determined by most of the readers (two).

ANALYSIS

Statistical analyses were performed with SPSS/PC Version 4.0.1 software. $^{23}$ For dichotomous exposure analyses, a comparison of two independent samples of exposed dry cleaning operators with unexposed controls was used. Due to non-normal distributions, continuous data for hepatic transaminase concentrations were assessed by the rank sum method (Mann-Whitney U test). Pearson $\chi^{2}$ statistics were used to compare the prevalence of transaminase abnormalities and sonographic changes of mild or greater degree, between the exposed and control groups. For ordinal analyses of trends across non-exposed, low, and high exposure groups, a MantelHaenszel test of linear association was used. ${ }^{24}$ Odds ratios (ORs) for sonographic changes were determined by logistic regression models regressing mild or greater parenchymal changes (dependent variable) on crude, subacute, and cumulative perchloroethylene exposure (independent variables). Adjusted ORs were also determined by including covariates for ethanol consumption (past six months), sex, body mass index, age, and serological evidence of active hepatitis (hepatitis B surface antigen or hepatitis $C$ antibody) and former hepatitis B infection (hepatitis B core antibody). Analyses were also conducted excluding Asian and native American subjects to 
Table 2 Biochemical and serological data by crude exposure

\begin{tabular}{lccl}
\hline $\begin{array}{l}\text { Hepatitis serum } \\
\text { measurements }\end{array}$ & $\begin{array}{l}\text { Non-exposed } \\
\text { Laundry workers } \\
(n=29)\end{array}$ & $\begin{array}{l}\text { Exposed } \\
\text { Dry cleaning operators } \\
(n=29)\end{array}$ & Reference range \\
\hline HBsAg (n(\%)) & $1(3 \%)^{\star}$ & 0 & \\
HCV (n(\%)) & $2(7 \%)^{\star}$ & $2(7 \%)^{\star}$ & \\
HBcAb (n(\%)) & $1(3 \%)$ & $8(28 \%)$ & \\
Biochemical tests (mean (SD)): & 26 & 27 & \\
n & $0 \cdot 5(0 \cdot 4)$ & $0 \cdot 6(0 \cdot 4)$ & $(0 \cdot 1-1 \cdot 2)$ \\
Total bilirubin (mg/dl) & $0 \cdot 1(0 \cdot 1)$ & $0 \cdot 1(0 \cdot 1)$ & $(0-0 \cdot 3)$ \\
Direct bilirubin (mg/dl) & $20(12)$ & $27(21)$ & $(0-50)$ \\
ALT (SGPT) (IU/ml) & $20(8)$ & $23(10)$ & $(0-41)$ \\
AST (SGOT) (IU/ml) & $20(13)$ & $29(29)$ & $(10-65)$ \\
GGT (IU/ml) & $58(15)$ & $59(12)$ & $(30-115)$ \\
Alkaline phosphatase (IU/ml) & $79(17)$ & $82(27)$ & $(60-110)$ \\
Glucose (mg/dl) & & \\
\hline
\end{tabular}

$\star$ Excluded from biochemical and sonographic analyses

assess whether ethnic differences in hepatic enzyme metabolism effected the association between perchloroethylene exposure and sonographic changes. Five of the 58 subjects selected (three from the non-exposed laundry group and two from the dry cleaning group) were identified as having serological evidence of active hepatitis (positive for hepatitis B surface antigen or hepatitis $C$ antibody). These subjects were excluded from hepatic transaminase and ultrasound analyses, reducing the subject number to 27 dry cleaners and 26 laundry workers for these analyses. All subjects were included, however, in logistic regression models for adjusted ORs that controlled for serological evidence of hepatitis as independent covariates.

\section{Results}

DEMOGRAPHIC CHARACTERISTICS

The exposed and control groups were similar for sex, body mass index, education, and alcohol consumption (table 1). Differences in age (46 y for dry cleaners $v 38 \mathrm{y}$ for controls) and duration of employment ( $20 \mathrm{y}$ for dry cleaners $v 5 \mathrm{y}$ for controls) reflect the fact that the job of dry cleaning operator is generally a career position for workers with seniority. Ethnic differences between the groups included an increased representation of Asians among dry cleaners $(24 \%)$, similar to industry reports of $20 \%-25 \%$. $^{7}$

\section{PERCHLOROETHYLENE EXPOSURE}

Among the 19 dry cleaners assessed by badge dosimetry, mean (range) eight hour time weighed average ( $8 \mathrm{~h}$ TWA) perchloroethyl- ene exposure was $15.8(0.4$ to 83$) \mathrm{ppm}$. All five operators who used dry to dry equipment installed within the preceding three years had exposure concentrations less than $15 \mathrm{ppm}$, with a mean (range) $8 \mathrm{~h}$ TWA single day exposure of $4.6(0.4$ to 9.3$) \mathrm{ppm}$. In contrast, six of the $14(43 \%)$ operators who used older dry to dry or transfer processes had concentrations greater than $15 \mathrm{ppm}$ (mean (range) $8 \mathrm{~h}$ TWA $19 \cdot 8$ (1.8-83) ppm).

HEPATITIS VIRUS SEROLOGICAL TESTING Hepatitis serum samples (table 2) showed three $(10 \%)$ laundry workers and two (7\%) dry cleaning operators to have active hepatitis (hepatitis B surface antigen ( $\mathrm{HBsAg}$ ) or hepatitis $\mathrm{C}$ antibody (HCV)). As noted, these participants were excluded from analysis of study outcomes. An increased prevalence of previous hepatitis $B$ infection among dry cleaners compared with laundry workers (28\% v 3\% positive for hepatitis B core antibody ( $\mathrm{HBcAg})$, respectively) is in a large part explained by the greater representation of Asians among the dry cleaning group, with five of nine (56\%) Asians positive for hepatitis B core antibody compared with only four of $49(8 \%)$ non-Asians. None of the Asian subjects, however, had evidence of active hepatitis (positive for hepatitis B surface antigen or hepatitis $\mathrm{C}$ antibody). The absence of a history of jaundice or hepatitis among subjects positive for hepatitis B core antibody indicates previous subclinical infection with subsequent immunity.

\section{BIOCHEMICAL TESTS}

Table 2 shows the biochemical test results, with figure 2(A) showing prevalence of increased ALT, AST, and GGT concentrations. Mean values tended to be higher for all hepatic transaminase concentrations in dry cleaners compared with laundry workers, although no differences were significant. Increased ALT concentrations were found in five $(19 \%)$ dry cleaners compared with one (4\%) laundry worker $(P=0.10)$; in all cases the rises in ALT were less than 1.5 times the upper limit of normal and had ALT:AST ratios greater than 1 . No significant differences in prevalences of abnormal AST or GGT concentrations were found between the two groups. Inclusion of all subjects, regardless of serology or exclusion of subjects positive for hepatitis B core antibody, showed similar distributions of mean hepatic transaminase activity and prevalence of abnormal
Figure 2 Prevalence of (A) abnormalities of hepatic transaminases (ALT, AST, GGT), and (B) hepatic ultrasonographic parenchymal changes (normal, mild, and moderate to severe) by perchloroethylene exposure.
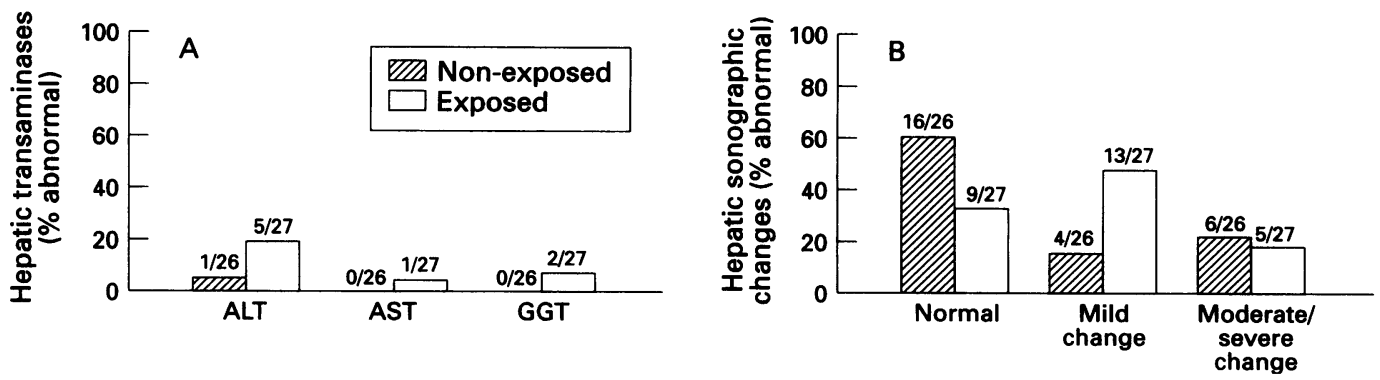
Table 3 Prevalence of hepatic ultrasonographic parenchymal changes by subacute and chronic perchloroethylene exposure

\begin{tabular}{lclllll}
\hline Perchloroethylene exposure & $n$ & Normal & Mild & $\begin{array}{l}\text { Moderate } \\
\text { to severe }\end{array}$ & Any & P value \\
\hline $\begin{array}{l}\text { Non-exposed (controls, } \mathrm{n}(\%)): \\
\text { Subacute: }\end{array}$ & 26 & $16(62)$ & $4(15)$ & $6(23)$ & $10(38)$ & \\
$\begin{array}{l}\text { New dry to dry operation } \\
\text { Old dry to dry transfer }\end{array}$ & 9 & $4(44)$ & $4(44)$ & $1(11)$ & $5(55)$ & $0.03 \dagger$ \\
$\begin{array}{l}\text { Current: } \\
<15 \text { ppm (8 h TWA) }\end{array}$ & 18 & $5(28)$ & $9(50)$ & $4(22)$ & $13(72)$ & \\
$\geqslant 15$ ppm (8 h TWA) & 12 & $6(50)$ & $5(42)$ & $1(8)$ & $6(50)$ & $0.02 \dagger$ \\
Cumulative: & 5 & 0 & $3(60)$ & $2(40)$ & $5(100)$ & \\
$<10^{\star}$ & 13 & $5(38)$ & $5(38)$ & $3(23)$ & $8(61)$ & $0.04 \dagger$ \\
$\geqslant 10$ & 14 & $4(29)$ & $8(57)$ & $2(14)$ & $10(71)$ & \\
\hline
\end{tabular}

*Process adjusted years $=$ (years wet transfer $)+\left(\frac{1}{2}\right.$ years dry to dry $)$

†Mantel-Haenszel test of trend ( $1 \mathrm{df}$ ) across non-exposed (control) and dichotomised low and high exposure groups for any (mild or moderate to severe) sonographic change.

Table 4 Odds ratios for hepatic parenchymal changes* by perchloroethylene exposure

\begin{tabular}{lll}
\hline Perchloroethylene exposure & Unadjusted OR (95\% CI) & Adjusted OR $(95 \%$ CI)† \\
\hline $\begin{array}{l}\text { Crude exposure } \\
\text { Subacute exposure }\end{array}$ & $3 \cdot 2(1 \cdot 04-9 \cdot 8)$ & $2 \cdot 5(0 \cdot 6-10 \cdot 1)$ \\
New dry to dry operation & $2 \cdot 0(0 \cdot 4-9 \cdot 3)$ & $0 \cdot 7(0 \cdot 1-5 \cdot 9)$ \\
Old dry or wet transfer operation & $4 \cdot 2(1 \cdot 1-15 \cdot 3)$ & $4 \cdot 2(0 \cdot 9-20 \cdot 4)$ \\
Cumulative & & \\
$<10 \ddagger$ & $2 \cdot 6(0 \cdot 7-10 \cdot 1)$ & $5 \cdot 1(0 \cdot 8-33 \cdot 1)$ \\
$\geqslant 10 \ddagger$ & $4 \cdot 0(1 \cdot 0-16 \cdot 3)$ & $1 \cdot 2(0 \cdot 2-7 \cdot 2)$ \\
\hline
\end{tabular}

*Any mild or greater sonographic change compared with unexposed control group; fadujsted for age, alcohol consumption, body mass index, sex, and serological evidence of active (hepatitis $C$ age, alcohol consumption, body mass index, sex, and serological evidence of active (hepatitis C †process adjusted years $=$ (years wet transfer $)+(1 / 2$ years dry to dry $)$.

transaminase concentrations in the exposed and control groups.

\section{HEPATIC SONOGRAPHIC TESTING}

The pattern of sonographic readings, interpreted as normal, mild, or moderate to severe change, differed significantly between the exposed dry cleaners and non-exposed laundry workers (fig 2(B)). Among laundry workers 16 of $26(62 \%)$ sonograms were interpreted as normal, compared with only nine of 27 (33\%) normal in the exposed group. Changes in hepatic parenchymal echogenicity between the two groups occurred chiefly in the mild category, with $48 \%$ of dry cleaners having mild abnormalities compared with only $15 \%$ among the unexposed group. About $20 \%$ of subjects in both groups had moderate to severe changes in parenchymal echogenicity. A significantly greater prevalence of any (mild or greater) hepatic parenchymal changes in dry cleaning operators than in non-exposed laundry workers $(67 \% v 39 \%, P<0.05)$ was found.

When exposed subjects were dichotomised relative to measures of either subacute, current, or cumulative exposure, the prevalence of hepatic parenchymal changes showed significant exposure-response trends across non-exposed, low, and high exposure groups (table 3). Similar trends were found relative to shop process and personal air sampling, classified according to whether the current measure of full shift exposure had been above or below 15 ppm TWA. This trend was greatest for the personal air sampling comparison, where hepatic parenchymal changes were found in all five subjects with exposures above $15 \mathrm{ppm}$, half of the 12 subjects with exposures below $15 \mathrm{ppm}$, and only $38 \%$ of the unexposed laundry workers. The exposureresponse trend was less evident for cumulative than subacute exposure; although significant, the prevalence of hepatic changes differed by only $10 \%$ between low and high cumulative exposure categories.

Table 4 shows the ORs that represents risk for hepatic parenchymal changes associated with perchloroethylene exposure. Overall, perchloroethylene exposure was associated with a threefold increase in risk of hepatic parenchymal changes. Due to a greater prevalence of mild or greater sonographic changes in the seven subjects with previous hepatitis $B$ infection (positive for hepatitis B core antibody, negative for hepatitis B surface antigen) compared with seronegative subjects $(86 \% v$ $48 \%$, respectively, $P=0 \cdot 10$ ), ORs for sonographic changes associated with perchloroethylene were also calculated with adjustment for the effects of hepatitic serology as well as age, sex, body mass index, and alcohol consumption; these were not changed materially compared with the unadjusted analysis (table 4). Exclusion of Asian and native American subjects did not effect the magnitude of crude or adjusted risk estimates, nor any exposureresponse trends. A strong dose-response relation was found only for subacute exposure after adjustment for confounding factors, with dry cleaners who used old dry to dry or wet transfer methods at fourfold increased risk of sonographic changes. An inverse doseresponse was found for cumulative exposure after adjustment for age, due to a particularly strong association between perchloroethylene exposure and hepatic sonographic changes in younger workers, with a stratum specific OR of 15 (95\% confidence interval $(95 \% \mathrm{CI})$ 1.33-170) for workers less than 35 years old.

To relate hepatic transaminase and ultrasonographic findings, abnormalities detected by each method were compared. All subjects (five in the exposed and one in the unexposed group) with raised ALT concentrations had moderate or greater parenchymal echogenicity. Only six of 28 subjects $(21 \%)$ with parenchymal sonographic changes had increases of any hepatic transaminase.

\section{Discussion}

Although acute hepatotoxicity is well described, little is known about the subacute and chronic effects of perchloroethylene or other organic solvents on the liver. Our findings indicate that subacute and possibly chronic hepatic parenchymal changes, generally of mild degree, are associated with perchloroethylene exposure at concentrations commonly experienced in community dry cleaning works. An exposure-response relation between parenchymal changes and solvent exposure was also found, with dry cleaning operators who used transfer or older dry to dry equipment at greatest risk. The effects seem most pronounced at younger ages (less than $35 \mathrm{y}$ ), but the small sample size limits inference on age related interactions. 
We detected hepatic effects with ultrasonographic imaging, generally in the absence of raised transaminases, at perchloroethylene concentrations below those ordinarily associated with hepatotoxicity. Clinical reports and case series have generally shown biochemical abnormalities related to perchloroethylene exposure only at concentrations greater than 100 ppm. ${ }^{1-6}$ In contrast, the mean eight hour TWA for perchloroethylene exposure for the samples collected in this study was $16 \mathrm{ppm}$, which is below the previous Occupational Safety and Health Administration (OSHA) permissible exposure concentration of 25 ppm, and raises concern about potential adverse health effects associated with the recent upward revision of the standard to 100 ppm. ${ }^{25}$ The presence of subclinical hepatic effects at the exposure concentrations found in this study emphasises the importance of improved engineering controls or substitution to non-solvent agents to minimise exposure. Our findings suggest that strategies for detecting liver injury with only hepatic transaminases may underestimate hepatotoxic effects in populations exposed to solvents. Hepatic imaging with ultrasound may be a sensitive marker for preclinical effects, providing a useful population surveillance tool in the setting of chronic solvent exposure.

Two other cross sectional studies that investigated dry cleaners with perchloroethylene exposures of less than $25 \mathrm{ppm}$, also found few biochemical abnormalities. As in our study, Lauwerys and associates found no significant difference in mean ALT or GGT concentrations in 22 dry cleaners compared with 33 non-exposed factory workers. ${ }^{26}$ Gennari and associates reported no significant difference in mean ALT in 141 dry cleaners compared with 130 non-exposed university students, and noted only a mild increase in sample mean GGT (12.4 $v 8.8 \mathrm{U} / 1, \mathrm{P}<0.05)$ and GGT-2 isoenzyme; no individual worker was noted to have an increase of any hepatic transaminase. ${ }^{27}$ Similarly, increases in transaminases were uniformly mild in our study, with no transaminase values exceeding 1.5 times the normal limits. The finding of sonographic hepatic changes in this context suggests that transaminases may be of limited use in detecting subclinical injury preceding the occurrence of prominent inflammation or necrosis.

Although the histological abnormalities associated with the sonographic changes found in this study cannot be specifically identified, two factors suggest that they represent predominantly steatosis. Firstly, increased hepatic echogenicity is strongly associated with fatty change, with sensitivity and specificity greater than $90 \%$, but is not as well correlated with fibrosis or cirrhosis in the absence of steatosis. ${ }^{12}{ }^{13}$ Secondly, the mild subacute parenchymal effects found in this study are most consistent with early changes such as steatosis. Fatty change has also been found consistently in histological samples from exposed workers with persistently elevated hepatic transaminase concentrations, ${ }^{8-10}$ ${ }^{28}$ and in animal models. ${ }^{29}$
This study has several limitations. Firstly, findings of parenchymal echogenicity do not allow histological interpretation of our results. The inability to distinguish fatty from fibrotic abnormalities allows no specific conclusions about severity or acuity of parenchymal changes in dry cleaners. The strong association between subacute exposure and parenchymal change suggests that these changes coexist with, and possibly obscure, chronic effects such as fibrosis. Secondly, both the cross sectional design of this study and use of qualitative exposure estimates do not allow assessment of a specific "no observable effects level" for hepatic changes related to perchloroethylene. Single shift exposure measurements on a limited number of workers does not allow assessment of individual day to day variability, and may not accurately reflect subacute exposure. Furthermore, exposure to perchloroethylene in the dry cleaning industry has generally declined with improved technology and regulatory changes; current exposure concentrations may thus not reflect previously higher burdens. Although use of perchloroethylene is now virtually ubiquitous in the dry cleaning industry, solvents used in the past, including other chlorinated and mixed aliphatic hydrocarbons, may also have contributed to hepatotoxicity. Thirdly, the clinical significance of the hepatic sonographic changes found in this study is unclear. Although the natural history of steatosis has not been well characterised, several studies of fatty liver associated with obesity and diabetes mellitus have raised concern about progression to fibrosis, or even cirrhosis, in the absence of significant hepatic inflammation. ${ }^{30}{ }^{31}$ Finally, the high overall prevalence of hepatic parenchymal changes limits specificity and thus the interpretation of abnormal sonograms in individual workers. Although previous hepatitis B infection, demographic factors including age, ethnicity, body mass index, and alcohol intake had minimal effect on the association between perchloroethylene exposure and hepatic parenchymal changes found in this study, the presence of these factors in general populations may further limit specificity of ultrasonography. Changes in hepatic parenchymal echogenicity associated with these factors have not been well characterised, nor has their potential interaction with percloroethylene to increase susceptibility to hepatic injury. The sensitivity of sonographic imaging in detecting subclinical changes may have benefit in early population surveillance of high risk groups.

In summary, subclinical hepatic effects seem to occur at relatively low concentrations of perchloroethylene exposure, well below the recently revised OSHA permissible exposure limits of $100 \mathrm{ppm}$. The extent to which these changes might develop into clinically significant liver disease is unknown. Our findings raise the concern that early reversible changes such as steatosis may go undetected by standard transaminase measurements; whether progression to irreversible fibrotic changes over a working career occurs is unknown, and 
should be an area of further investigation. Further application of ultrasonography in workers exposed to perchloroethylene and other suspected hepatotoxicants will show the usefulness of this method for early detection of liver injury.

CAB was supported by a Clinical Fellowship from the Agency for Toxic Substances and Disease Registry (ATSDR; Atlanta, GA). Partial support was provided by a research grant from the Department of Environmental Health, University of Washington (Seattle, WA). We are indebted to Richard Willson, MD (University of Washington, Department of Gastroenterology) for critical review of the study proposal and data collection; Gil Titus (Advanced Technologies Laboratory) for technical assistance with ultrasonography; Gabrielle Totangi, CIH, and Norunn Ronhovde (Batelle Seattle Research Center) for assistance in industrial hygiene sampling and subject recruitment.

1 Coler HR, Rossmiller HR. Tetrachloroethylene exposure in a small industry. Arch Ind Hyg Occup Med 1953;8: 227-33.

2 Hughes JP. Hazardous exposure to some so-called safe solvents. $¥ A M A 1954 ; 156: 234-7$.

3 Stewart RD, Erley DS, Schaffer AW, Gay HH. Accidental vapor exposure to anesthetic concentrations of a solvent containing tetrachloroethylene. Ind Med Surg 1961;30: 327-30.

4 Stewart RD. Acute tetrachloroethylene intoxication. भAMA 1969;208:1490.

5 Hake CL, Stewart RD. Human exposure to tetrachloroethylene: inhalation and skin contact. Environ chloroethylene: inhalation and

6 National Institute for Occupational Safety and Health (NIOSH). Current intelligence bulletin 20, tetrachloroethylene (perchloroethylene). Cincinnati: DHEW (NIOSH), 1978. (No 78-112.)

7 Cantin J. Overview of exposure pathways. In: Bergin G, ed. International roundtable on pollution prevention and control in the drycleaning industry. United States Environmental Protection Agency (EPA) Proceeding (Office of Pollution Prevention and Toxics). Washington, DC: EPA, 1992:5-22. (Report No EPA/774/R-92/002.)

8 Guzelian P, Mills S, Fallon HJ. Liver structure and function in print workers exposed to toluene. $₹$ Occup Med tion in print work

9 Sotaniemi EA, Sutinen S, Arranto AJ, Pelkonen RO. Liver injury in subjects occupationally exposed to chemicals in low doses. Acta Med Scand 1982;212:207-15.

10 Redlich C, West B, Fleming L, True L, Cullen M, Riely C. Clinical and pathologic characteristics of hepatotoxicity associated with occupational exposure to dimethylformamide. Gastroenterology 1990;99:748-57.

11 Saverymuttu SH, Joseph AE, Maxwell JD. Ultrasound scanning in the detection of hepatic fibr

sis. B M f Clin Res Ed 1986;292:13-5. de Korte PJ, van den Tweel J, van der Loos T, Veldhuyzen
van Zanten GO, Lustermans FA. Cirrhosis and liver echogenicity. Neth 7 Med 1987;30:17-20.

13 Gosink BB, Lemon SK, Scheible W, Leopold GR Accuracy of ultrasonography in diagnosis of hepatocellular disease. AfR Am $\mathcal{F}$ Roentgenol 1979;133:19-23.

14 Williams DMJ, Smith PM, Taylor KJW, Crossley IR, Duck $\mathrm{BW}$. Monitoring liver disorders in vinyl chloride monomer workers using grey scale ultrasonography. Br f Ind Med 1976;33:152-7.

15 Taylor KJW, Williams DMJ, Smith PM, Duck BW. Greyscale ultrasonography for monitoring industrial exposure to hepatotoxic agents. Lancet $1975 ;$ i: $1222-4$

16 Lelback WK. Epidemiology of alcoholic liver disease. Prog Liver Dis 1976;5:494-515.

17 Bray GA. Definition, measurement, and classification of the syndromes of obesity. Int $\mathcal{F}$ Obesity 1978;2:99-112.

18 Materna BL. Occupational exposure to perchloroethylene in the dry cleaning industry. Am Ind Hyg Assoc $\mathcal{F} 1985$; in the dry clea

19 den Otter W. Evaluation of new generation dry cleaning equipment. In: Bergin G, ed. International roundtable on pollution prevention and control in the drycleaning industry. United States Environmental Protection Agency (EPA) Proceedings (Office of Pollution Prevention and Toxics).
Washington, DC: EPA, 1992:16-9. (Report No EPA/774/R-92/002.)

20 NIOSH. Manual of analytical methods, 2nd ed. Vol 3. Cincinnati : National Institute of Occupational Safety and Health, US Department of Health, Education, and Welfare, 1977. (Publ No 77-157C-S335-1-S391-8.)

21 Scatarige JC, Scott WW, Donovan PJ, Siegelman SS, Sanders RC. Fatty infiltration of the liver: ultrasonographic and computed tomographic correlation. f Ultrasound Med 1984;3:9-14.

22 Cohen J. Weighted kappa: nominal scale agreement with provision for scaled disagreement or partial credit. Psychol Bull 1968;70:213-20.

23 SPSS. Statistical package for the social sciences. Chicago: SPSS/PC, 1991.

24 Mantel N, Haenszel W. Statistical aspects of the analysis of data from retrospective studies of disease. $\mathcal{F}$ Natl Cancer Inst 1959;22:719-48.

25 Code of Federal Regulations (Labor), 29-CRF 1910.1000: July 1,1993 Revision. Washington: Department of Labor, 1993:18.

26 Lauwerys R, Herbrand J, Buchet JP, Bernard A, Gaussin J. Health surveillance of workers exposed to tetrachloroethylene in dry-cleaning shops. Int Arch Occup Environ Health 1983;52:69-77.

27 Gennari P, Naldi M, Motta R, et al. Gamma-glutamyltransferase isoenzyme pattern in workers exposed to tetrachloroethylene. Am $\mathcal{F}$ Ind Med 1992;21:661-71.

28 Dossing M, Arlien-Soborg P, Petersen LM, Ranek L. Liver damage associated with occupational exposure to organic solvents in house painters. Eur $\mathcal{f}$ Clin Invest 1983;13:151-7.

29 Balazs T, Murray TK, McLaughlan JM, Grice HC Hepatic tests in toxicity studies on rats. Toxicol Appl Pharmacol 1961;3:71-9.

30 Diehl AM, Goodman Z, Ishak KG. Alcohol-like liver disease in non alcoholics: a clinical and histologic comparison with alcohol-induced liver injury. Gastroenterology 1988;195:1056-62.

31 Powell EE, Cooksley WGE, Hanson R, Searle J, Halliday JW, Powell LW. The natural history of nonalcoholic steatohepatitis: a follow up study of $\mathbf{4 2}$ patients for up to 21 years. Hepatology 1990;11:74-80. 